\title{
0 "Sonho de Rose": políticas de saúde pública em assentamentos rurais
}

\section{Rose's Dream: public health policies in rural land settlements}

Diego Soares

Mestre em Antropologia Social (PPGAS - UFRGS)

Pesquisador Associado ao Núcleo de Antropologia e Cidadania

(UFRGS)

E-mail: soares2bræyahoo.com.br

\section{Resumo}

Este artigo partiu de uma breve reflexão sobre a tensão entre os princípios de universalidade e a especificidade cultural dos usuários das políticas de saúde pública, procurando inserir a discussão sobre saúde coletiva em assentamentos rurais dentro deste eixo reflexivo. Apresenta dados etnográficos sobre um projeto de extensão universitária realizado no assentamento "19 de Setembro", localizado nas imediações da região metropolitana de Porto Alegre (RS). A partir da experiência de implementação de uma "farmacopéia popular" nesse assentamento, discute-se um modelo dialógico de intervenção no campo da saúde pública, um modelo esteja mais apropriado ao diálogo com a alteridade e com a inclusão de práticas terapêuticas alternativas ao modelo biomédico. Para finalizar, desenvolve algumas reflexões iniciais sobre os usos diferenciados dos dispositivos institucionais a partir de uma contraposição entre a análise de Foucault sobre as tecnologias de poder e as observações críticas introduzidas por Michel de Certeau, o qual analisa os usos dos dispositivos, as artes de fazer que subvertem os modelos disciplinares.

Palavras-chaves: Políticas de saúde pública; Exclusão social; Assentamentos rurais; Saberes tradicionais; Reforma agrária. 


\section{Abstract}

In this paper, there is a reflection on the tension between the principle of universality and the cultural specificity of users of the Public Health system, inserting the discussion about collective health in rural land settlements in this axis. After presenting some statistical data about health conditions in rural land settlements, ethnographic data on a project of university extension accomplished in a rural settlement located in the metropolitan area of Porto Alegre (RS) is presented. A dialogic model of intervention in the field of public health, respecting cultural differences and including alternative therapeutic practices to the biomedical model is discussed. As conclusion, some reflections are made on the different uses of the institutional devices starting from an opposition between the analysis of Foucault about the technologies of power and the critical observations introduced by Michel de Certeau, more concerned with analyzing the uses of the devices, the arts of doing that subvert the models of discipline.

Keywords: Public Health Policies; Social exclusion; Land Settlements; Traditional Knowledge; Land reform.

\section{Introdução}

A preocupação com as condições de saúde das populações, a efetivação de práticas e a emergência de instituições e saberes sobre doença, o risco e a sua relação com a organização social e econômica das sociedades, pode ser descrita a partir de duas perspectivas complementares: de um lado, como tecnologias disciplinares que agem sobre o corpo dos indivíduos (forças de produção), tendo como objetivo a promoção da saúde do corpo social (conceito de biopolítica, de Michel Foucault); de outro, como o resultado de um conjunto de lutas sociais e táticas que acompanham o uso dos dispositivos institucionais (lutas pela conquista do direito à saúde, incluindo táticas de implementação de práticas terapêuticas alternativas ao modelo biomédico). Essas abordagens estão presentes nas discussões sobre a formação, no Brasil, de um sistema de seguridade social e, por força de extensão, das políticas de saúde pública: por um lado, a seguridade social seria o resultado da conquista de direitos sociais pelos assalariados; por outro, uma intervenção do Estado, tendo em vista a produção das condições necessárias para o desdobramento da ordem social capitalista (Noronha, 2005, p.33).

Neste artigo, não se pretende negligenciar nenhum desses dois aspectos, pois, entende-se que uma política pública é, ao mesmo tempo, um conjunto de técnicas de intervenção e um campo de luta política. O objetivo aqui é desenvolver uma reflexão a partir desse pressuposto inicial, o que certamente influenciará na forma como será conduzida a discussão sobre o tema da exclusão social e as políticas públicas na área de saúde.

\section{Políticas de Saúde Pública: entre o universal $e$ o específico}

A partir da Constituição de 1988, a saúde passou a ser "direito de todos e dever do Estado, garantido mediante políticas sociais e econômicas que visem à redução do risco de doença" (Brasil, 1988). A universalidade do acesso aos serviços públicos de saúde em todos os níveis de assistência está inscrita na lei que 
regula as ações e serviços de saúde ${ }^{1}$, sendo uma das principais diretrizes da política nacional de seguridade social. Ao mesmo tempo, os princípios de participação da comunidade e descentralização administrativa - regionalização e municipalização dos serviços - apontam para a necessidade de se administrar o sistema levando em conta as especificidades sociais, econômicas e culturais das diferentes regiões do país.

A mesma tensão entre o universal e o específico é expressa a partir de outras contradições que perpassam as políticas públicas na área de saúde: conflito entre a objetividade científica do modelo biomédico e a subjetividade fenomenológica do paciente e do terapeuta; entre diretrizes provenientes de modelos normativos que abordam a doença, mas não o doente, e a necessidade de levar em conta as particularidades próprias a cada sujeito (a sua cultura, o seu modo de vida); o conflito entre o ser humano (universal, indivíduo biológico) percebido como objeto material de ciência e fechado em um quadro de valores normativos ou até mesmo considerado como mero consumidor de serviços (usuário), e o sujeito singular que emerge em um ambiente histórico, social, ecológico e cultural específico (Paul, 2005, p.73-75). A ação do modelo biomédico que disciplina os corpos buscando a maximização da sua utilidade produtiva não atua em um campo vazio de sentidos, mas entra em relação (conflituosa ou não) com um sujeito que escapa do seu olhar ordenador, dos seus sistemas de classificação. Isso ocorre porque o corpo não é apenas um corpo biológico, mas um corpo humanizado pela cultura.

Foi dentro deste debate que se inseriu toda a discussão sobre políticas de saúde voltadas para os setores mais pobres da população urbana, assim como para as sociedades indígenas, comunidades negras (remanescentes de quilombo) e, ultimamente, para a população do meio rural. Como essas discussões abrangem as diferentes concepções de doença, risco e práticas de precaução vigentes numa sociedade complexa e heterogênea como a brasileira, também é uma boa forma de abordar a discussão sobre tecnologias de intervenção e lutas sociais. Este será o nosso ponto de partida para pensar as políticas públicas de saúde voltadas para o atendimento da demanda das populações que vivem em assentamentos rurais.

\section{Como Pensar a Saúde Pública em}

\section{Assentamentos Rurais}

Apesar de a luta no campo da reforma agrária também se fazer presente na produção e na interpretação dos dados estatísticos, existem algumas fontes confiáveis que podem fornecer um quadro geral, como é o caso do I Censo de Reforma Agrária do Brasil (Schmidt, 1998), que traz dados sobre assentamentos criados até 1996, abrangendo diferentes aspectos sociais e econômicos (até na área da saúde pública); e o extraordinário trabalho que vem sendo desenvolvido pelo Banco de Dados da Luta pela Terra (Dataluta, 2004), que traz estatísticas sobre número de assentamentos por região e ano, abrangendo um período que vai de 1942 a 2004. São essas as fontes que serão usadas aqui para fornecer um quadro geral sobre os assentamentos rurais, procurando abordar brevemente algumas variáveis importantes.

Os dados do censo foram produzidos a partir de uma amostra do número total de assentamentos criados pelo Incra entre 1964 e 1996. É importante lembrar que nem todos os assentamentos foram criados pelo governo federal, pois uma parte deles foi instituída pelos governos estaduais, principalmente durante o Governo Collor, quando houve uma estagnação da política nacional de reforma agrária e um aumento considerável das ações políticas no campo (Navarro e col., 1999). Os dados já estão um pouco desatualizados, pois não levam em conta os assentamentos instituídos a partir da segunda metade da década de 1990, no entanto, podemos superar essas limitações se estivermos dispostos a fazer uma leitura pouco pretensiosa desses índices. Ao invés de abordarmos os dados como um retrato fiel da realidade, vamos abordálos como indicadores de um conjunto de elementos que devem ser pensados quando nos propomos abordar o problema da saúde pública nos assentamentos rurais. Um dos pontos positivos do censo é que os dados são organizados tendo em vista as diferenças regionais, o que já é uma grande conquista, pois permite analisar os itens de forma comparativa.

A idéia aqui é apresentar dados do censo que são pertinentes ao desenvolvimento do tema deste arti-

1 Lei $N^{0} .8 .080$, de 19 de Setembro de 1990. 
go. Levando em conta que saúde pública não diz respeito apenas ao atendimento médico e ao tratamento das doenças em nível individual, procuro interpretar alguns dados sobre condições hidrossanitárias, moradia, fonte de água e de energia utilizadas e, por último, a existência e a qualidade dos serviços de saúde nos assentamentos rurais.

No que se refere à fonte de água utilizada nos assentamentos, o censo aponta que o quadro nacional se compõe de três tipos predominantes de fontes fornecedoras de água, o poço (46,07\%), o riacho (14,17\%) e a cacimba (13,02\%), não sendo muito significativa a variação entre um estado e outro. As condições hidrossanitárias, no geral, são precárias, sendo que uma parte significativa não respondeu à pergunta dos pesquisadores, o que indica a ausência de qualquer uma das opções oferecidas no questionário na época em que os dados foram coletados. Conforme as conclusões do estudo, um grande número de assentados não tem acesso às condições mínimas de segurança hidrossanitária, principalmente no norte e no nordeste do Brasil, onde o acesso à água encanada é menor do que nas demais regiões do país (Schmidt, 1998, p.39).

Os dados do censo apontam que as condições de habitação são melhores, com um baixo índice de assentados ainda vivendo em barracas de lona ou habitações provisórias. As moradias são predominantemente de: madeira (31,90\%), taipa $(28,20 \%)$ e alvenaria $(22,99 \%)$, com pouca diferenciação regional ${ }^{2}$. No que se refere às fontes de energia, existem diferenças regionais significativas: enquanto no Sul e no Sudeste prevalece o uso da energia elétrica, nas demais regiões é mais freqüente o uso de querosene e óleo diesel ${ }^{3}$.

A área de saúde também foi avaliada em termos da existência e da qualidade de serviços básicos, como hospital, posto de saúde e agentes de saúde, tanto nos assentamentos como nos seus respectivos municípios. Esses dados foram prejudicados por um alto índice de beneficiários que não responderam, mas, em geral, a avaliação foi negativa, sendo o difícil acesso aos hospitais mencionado como a carência maior. Ao mesmo tempo, o censo sugere que a maioria dos ser- viços na área de saúde está disponível nos municípios e não dentro dos assentamentos, o que implica, por um lado, na necessidade de se negociar com o poder público local formas de acesso aos serviços já existentes e, por outro lado, a necessidade de ampliação desses serviços tendo em vista um aumento da demanda local. Ainda na área de saúde, o estudo indica que as doenças mais comuns são: gripe (32\%), verminose (14\%) e diarréia (9,9\%). Esse índice prevalece em todas as regiões, com uma pequena alteração na região Norte, onde a malária é muito comum $(15,46 \%)$ (Schmidt, p. 43). Essas doenças geralmente estão associadas a más condições hidrossanitárias e ausência de um sistema de saneamento adequado.

Os dados apresentados pelo censo estão desatualizados, mas nos fornecem um quadro geral da situação dos assentamentos implementados até a segunda metade da década de 1990. Ao abordar questões tão complexas do ponto de vista quantitativo, perde-se, certamente, o sabor local dos dilemas enfrentados no dia-a-dia. Mais do que isso, uma análise como esta não consegue abordar o saber e as estratégias colocadas em práticas pelos próprios assentados para enfrentar suas dificuldades na área de saúde. Uma visão geral não consegue identificar os casos bem-sucedidos, pois a finalidade do censo é apontar tendências, sugerir hipóteses que possam alimentar estudos qualitativos, sejam eles etnográficos ou não. As pesquisas qualitativas nessa área são poucas ou quase inexistentes, a maioria dos estudos aborda esse tema como um dado complementar. Muitos seriam os avanços se fosse possível relacionar dados mais abrangentes, como os que foram comentados aqui, com estudos de caso sobre estratégias locais, sejam elas promovidas pelo governo ou pelos próprios assentados.

O desenvolvimento de projetos na área de saúde voltados para a realidade dos assentamentos deve levar em conta a diversidade de situações, tanto no que se refere às características socioculturais da população, mas também no que se refere às diferenças ambientais, que mudam muito entre uma região e outra. Por outro lado, o Banco de Dados da Luta pela Terra

\footnotetext{
2 Habitações de madeira predominam no Centro-Oeste (49, 17\%), Norte (50,89\%) e Sul (73,46\%). No Nordeste predomina a moradia de taipa (45,35\%); e no Sudeste a de alvenaria (65,38\%) (Schmidt, p. 37).

3 Energia elétrica: Sudeste (49,9\%) e Sul (47, 9\%); querosene e óleo diesel: Norte (64,3\%), Centro-Oeste (50,7\%) e Nordeste (48\%) (Schmidt, p.41).
} 
apresenta números significativos: entre 1942 e 2004, foram instituídos mais de seis mil assentamentos, abrangendo uma população de 8 oo mil famílias e uma área de quase 35 milhões de hectares. A maior parte desses assentamentos foi implementada na segunda metade da década de 1990 e está localizada em todas as regiões do Brasil. Também foi nesse período que ocorreu um aumento considerável das ocupações de terra e outras mobilizações políticas no campo da reforma agrária. O que se percebe, portanto, é que o número de assentamentos rurais é significativo, e que a maioria foi implementada como resposta à pressão que os movimentos sociais vêm exercendo sobre o poder público. Sabemos que o perfil da população envolvida nessas mobilizações tem mudado consideravelmente, principalmente em estados como São Paulo e Rio de Janeiro, onde a maioria é proveniente das grandes cidades. No entanto, também não resta dúvida de que se trata de pessoas que se encontram numa situação de pobreza, vivendo em condições de saúde coletiva inadequadas, como é o caso dos assentados que são provenientes das favelas urbanas.

\section{Assentamento 19 de Setembro: paisagem e cenário}

\section{Paisagem}

O 19 de Setembro está localizado nas imediações da zona urbana de Guaíba ${ }^{4}$, uma pequena cidade que fica nos arredores de Porto Alegre, capital do Rio Grande do Sul. São mais de 400 hectares, onde vivem atualmente vinte e cinco famílias. A área, dividida em 37 lotes ${ }^{5}$ de onze hectares, está localizada a três quilômetros dos bairros populares Cohab e Santa Rita ${ }^{6}$. Devemos considerar, portanto, que apesar de se tratar aqui de uma zona rural ${ }^{7}$, ela se encontra em interface com o perímetro urbano.

As terras do assentamento são divididas pela BR116 , formando dois setores, denominados aqui de "se- tor A" e "setor B”. No “setor B”, está localizada a agrovila, onde vive a maior parte das famílias e cujo acesso é dado por uma estrada de chão, que perpassa as terras dos assentados. Foi nesse setor que as famílias se estabeleceram de forma definitiva, após uma tentativa infeliz de habitação no "setor A", onde teve início o processo de humanização do território. Essa primeira migração do grupo ocorreu cinco meses após a chegada das famílias, quando a primeira agrovila, formada ainda por barracos de lona, foi alagada devido às chuvas de inverno.

A atual agrovila fica em uma região mais afastada do perímetro urbano, onde as terras são mais altas e as inundações menos freqüentes, constituindo-se um aglomerado de casas de alvenaria e madeira, distribuídas em forma de semicírculo, tendo no seu interior uma praça onde está localizada a "associação". É ali que ocorrem as assembléias gerais, as reuniões da coordenação e do conselho comunitário, assim como as cerimônias religiosas e outras atividades e comemorações especiais. Essa associação também funciona, aos finais de semana, como "bar", freqüentado à noite pelos moradores e por visitantes ocasionais dos bairros vizinhos. A praça central ainda conta com uma área aberta ocupada geralmente pelas crianças, principalmente na parte da manhã, quando é comum percebê-las correndo de um lado para o outro, subindo em árvores, praticando esportes e jogos infantojuvenis. O complexo também tem uma escola primária, que fornece ensino fundamental (até a $4^{\mathrm{a}}$ série), um campo de futebol e duas canchas de bocha, onde os homens se reúnem para jogar nos finais de semana.

No "setor B", os terrenos onde se encontram as casas não ficam junto aos lotes, mas fragmentados em parcelas localizadas em diferentes regiões do assentamento, formando uma geografia de retalhos que só os próprios proprietários conseguem delimitar com precisão. No entanto, como os terrenos residenciais são grandes, muitas famílias possuem hortas, galpões e pequenos açudes em suas imediações.

\footnotetext{
4 A área ocupada pelo 19 de Setembro está mais precisamente localizada no km 297 da BR-116.

5 Essa diferença entre número de famílias e número de lotes ocorre porque muitas dessas famílias são extensas, compostas, muitas vezes, de mais de um beneficiário.

6 Conforme os dados fornecidos pela Secretaria de Planejamento da Prefeitura Municipal de Guaíba, a população total da cidade é de 100 mil habitantes, dos quais $40 \%$ são residentes nos bairros Cohab e Santa Rita.

7 A definição de zona rural assume aqui o sentido de área destinada à exploração extrativa agrícola, pecuária ou agroindustrial.
} 
O "setor A" fica do outro lado da BR-116, mais próximo da zona urbana. 0 acesso a esse setor se dá através de uma estrada de chão, que cruza em frente a oito lotes de terra, distribuídos entre seis famílias. A ocupação definitiva desta parte do assentamento ocorreu um pouco mais tarde, em outubro de 1992, quando um grupo de beneficiários migrou da agrovila e se estabeleceu ali. Nesse setor as casas estão localizadas junto aos lotes, possibilitando uma integração maior entre a morada e o ambiente de trabalho.

A grande maioria das casas do 19 de Setembro é de alvenaria, mas ainda persistem algumas residências de madeira, construídas em mutirões realizados ainda nos primeiros anos de assentamento ${ }^{8}$. Hoje em dia, todas as famílias têm acesso à energia elétrica e à água encanada ${ }^{8}$. 0 ambiente interno dessas moradias é, com poucas exceções, ornamentado com os signos da sociedade moderna, como os eletrodomésticos tão comuns nas residências urbanas, que convivem de forma harmoniosa com bandeiras e quadros do MST.

As terras do 19 de Setembro estão localizadas, em termos geográficos, nas proximidades da planície aluvial do lago Guaíba. Segundo os técnicos da equipe de extensão da universidade, em mais de 9o\% da área predominam solos de várzea que apresentam sérios problemas de drenagem. Tendo em vista a qualidade do solo, a sua vocação natural seria de cultivo do arroz irrigado. No caso de culturas de "sequeiro", seria necessária a implementação de sistemas de drenagem de alto custo econômico. Apenas uma pequena parcela de $10 \%$, denominada pelos assentados de “Cerrito", está localizada em uma topografia mais elevada que apresenta solos bem drenados, mas de baixa fertilidade natural. Essa área é de extrema importância para a subsistência das famílias, sendo destinada à produção de culturas de autoconsumo e forragem animal ${ }^{10,11}$. Esse dado sobre a qualidade do solo revela um aspecto importante do processo de assentamento, pois os assentados são provenientes de uma região onde predominam terras bem drenadas, denominadas "terras altas", onde eles plantavam culturas de sequeiro, como milho, aipim, feijão e soja. A mudança para o assentamento teve um forte impacto na relação dessas famílias com o trabalho e o meio ambiente, tanto do ponto de vista técnico como simbólico.

Conforme o diagnóstico realizado pela equipe de extensão da universidade, os assentados também enfrentam sérios problemas ambientais devido à poluição causada pelas lavouras de arroz localizadas nas imediações, que deságuam herbicidas e adubos químicos de alta solubilidade no "Canal da Celupa", sistema de drenagem que cruza pelo interior do assentamento. Outra fonte de poluição tem sua origem nos afluentes domésticos dos núcleos urbanos vizinhos e do próprio assentamento, como substâncias orgânicas e detergentes, que também deságuam neste mesmo canal ${ }^{11}$. O reservatório de água do "Arroio do Conde", regulado por uma barragem com comportas, encontra-se nas terras do assentamento e está diretamente interligado com o canal. Este complexo de drenagem abastece as grandes lavouras de arroz localizadas na região e é um fator de conflito constante, pois a abertura das comportas da barragem, que são controladas pelos proprietários das terras contíguas ao 19 de Setembro, ocasiona a inundação de uma área significativa do assentamento, utilizada como reserva de pastagem para os animais.

O sistema de produção predominante entre os assentados é a pecuária de leite associada à horticultura. Juntas, essas duas atividades representam as principais fontes de renda das famílias. Essa produção é complementada por culturas de autoconsumo, como o feijão, a mandioca, o milho e a batata-doce, que sofrem fortes restrições devido à qualidade dos solos. Recentemente, a partir de 2002, algumas famílias têm

\footnotetext{
8 As casas de alvenaria são em maior número do que as de madeira, contrariando a média habitacional dos assentamentos da região Sul, onde o material predominante utilizado na construção das habitações é a madeira. Ver Schmidt et al., 1998 , p.38.

8 Esses dados indicam que o 19 de Setembro encontra-se, no que se refere às fontes de energia e de água, em uma situação favorável em relação à média da região Sul. Ver Schmidt et al., 1998, p. 84-85.

9 “Cultura de Sequeiro" são as culturas, ou produtos agrícolas, que só podem ser cultivados em solos secos, sem muita umidade (Ex: aipim, feijão, milho, batata-doce etc.).

10 O Cerrito é dividido em partes iguais por todos os beneficiários.

11 UNISOL; SESU/MEC. Relatório de pesquisa: diretrizes para revitalização do espaço sócio-produtivo do Assentamento 19 de Setem-

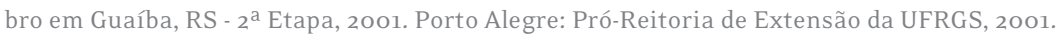


investido na produção de arroz irrigado. Devido ao sucesso dessas experiências de vanguarda, apoiadas pelo diagnóstico técnico da equipe de extensão, assim como por uma conjuntura política favorável em nível nacional ${ }^{12}$, boa parte das famílias encontra-se em processo de elaboração de projetos voltados para a rizicultura $^{13}$. A comercialização do excedente da produção do leite e das hortaliças é realizada pelos próprios assentados, diretamente ao consumidor. As entregas são realizadas de carroça, bicicleta, carro ou moto. A "clientela”, em alguns casos, inclui mercados, padarias e outros estabelecimentos localizados nos bairros populares da cidade.

\section{Cenário}

Em 2001, existiam no Rio Grande do Sul duas centenas de assentamentos, onde viviam nove mil famílias, que juntas ocupavam uma área com mais de 150 mil hectares (Fernandes, 2004). O processo histórico de implementação desses assentamentos pode ser dividido em três fases históricas. A primeira delas teve início em 1978 e perdurou até 1984, caracterizandose pela retomada das lutas sociais no campo. A segunda fase ocorreu entre 1985 e 1988, período em que foi apresentado o "I Plano Nacional de Reforma Agrária”, marcado também por uma atuação mais intensa do Movimento dos Trabalhadores Rurais Sem Terra (MST). Conforme esta periodização, o 19 de Setembro foi implementado na terceira fase, que teve início no final da década de 1980, caracterizada por um refluxo da questão agrária em nível nacional e por um deslocamento geográfico dos assentamentos em direção à região metropolitana de Porto Alegre e ao noroeste do estado (Navarro e col., 1999).

A década de 1980 foi marcada, com o final da ditadura militar, por uma conjuntura de abertura política, com o surgimento de novas lutas pelo acesso a terra, moradia e outros direitos civis que culminaram na promulgação, em 1988, da nova Constituição Brasileira (Gohn, 2002). Foi nesse contexto, de ampla mobilização popular, que as famílias que vivem no 19 de Setembro participaram de discussões sobre reforma agrária organizadas por agentes do MST. Esses agentes circulavam pelas regiões interioranas do estado em busca de adeptos para os novos acampamentos que estavam sendo organizados. As reuniões eram secretas e, na maioria das vezes, realizadas na casa de algum simpatizante ou, quando possível, nos sindicatos de trabalhadores rurais. Nessa época, conforme o relato dos assentados do 19 de Setembro, era comum se ouvir falar sobre peripécias dos colonos que participaram do acampamento na Encruzilhada Natalino, assim como de suas conquistas em Macali (1979), Brilhante (1979) e Annoni (1985). Essas histórias, que circulavam através de redes de parentesco e compadrio, acabaram incentivando a entrada na "luta" de muitos sem-terra, pois indicavam a possibilidade concreta de conseguir terra através do ingresso nas ações políticas promovidas pelo MST.

As mobilizações no campo aumentaram consideravelmente durante o início do Governo Collor (1991), devido ao seu posicionamento passivo em relação à reforma agrária, o que contrariou as expectativas de milhares de sem-terras. 0 que esses agricultores exigiam era o reconhecimento, por parte do Estado, do que eles entendiam como um "direito constitucional", ou seja, um direito de ter a sua própria terra para trabalhar. Esse momento histórico ainda está vivo na memória das famílias do 19 de Setembro. Durante a pesquisa de campo, muitos deles comentaram que tinham "esperança" de que, com a promulgação da nova constituição, eles finalmente teriam os seus "direitos" reconhecidos pelo Estado. No entanto, nada disso ocorreu e, mais uma vez, o destino lhes reservou o gosto amargo do descaso governamental.

Os dados sobre as ocupações de terra realizadas pelo MST revelam a intensificação do conflito agrário no estado: se em 1988 foi realizada uma única ocupação, entre 1989 e 1991, o número de ocupações de terra subiu para doze. Essas mobilizações foram acompanhadas de perto pelos fazendeiros e mais de uma vez acabaram na primeira página dos jornais de grande circulação. Christa Berger realizou um levantamento sobre todos os títulos e manchetes do

\footnotetext{
12 Novas linhas de financiamentos implementadas pelo Governo Lula.

13 Os dados levantados através da aplicação de questionários demonstram que mais de 9o\% das famílias produzem leite. Este percentual cai para 70\% em relação à horticultura. A produção de arroz, em processo de evolução, já passa dos 30\%. Culturas de autoconsumo são produzidas por mais de $70 \%$ das famílias.
} 
jornal Zero Hora que fizeram referência ao MST, publicados entre 1990 e 1993. Durante 1990, por exemplo, as ações do MST foram mencionadas 300 vezes. Esse número subiu para 463, em 1991 (2003, p.147). Muitas dessas notícias referem-se a ocupações que tiveram entre seus protagonistas as famílias que hoje se encontram assentadas em municípios localizados nas imediações da região metropolitana de Porto Alegre.

O nome do assentamento 19 de Setembro foi uma homenagem à data que marca a primeira ocupação realizada pelos assentados, ainda em 1989, junto com outras 1500 famílias ${ }^{14}$. Trata-se de um marco simbólico significativo que marca o início daquilo que eles denominam como a luta, palavra que sintetiza o conjunto de ações históricas das quais eles participaram: ocupações de terra e prédios públicos, longas caminhadas pelas rodovias do estado, acampamentos, greves de fome, encontros e atividades internas do movimento, conflitos com as "forças ruralistas" e com a Brigada Militar, reuniões com representantes do governo estadual e federal, passeatas no centro de Porto Alegre e outras cidades do interior do estado. A situação mais dramática ocorreu em agosto de 1990, quando um conflito no centro de Porto Alegre abalou a opinião pública gaúcha. Foi somente após esse episódio, que teve como resultado dezenas de manifestantes feridos e a morte de um soldado, que o governo estadual resolveu atender a parte das reivindicações exigidas pelos manifestantes (SJP/RS, 1990; Fernandes, 200o). Esse conflito foi manchete nos principais jornais do país, além de ter sido matéria de romances, artigos científicos, teses acadêmicas e revistas populares, como a Isto É e a Veja (Berger, 2003).

Foi nesse contexto que o então governador Alceu Collares, através da lei estadual 9.411, editada no dia 5 de novembro de 1991, cedeu à reforma agrária 70\% das Estações Experimentais e outras propriedades agricultáveis do Estado que não estivessem tendo um aproveitamento adequado (Rio Grande do Sul, 1991). Entre essas terras estava uma área do Instituto de Previdência do Estado do Rio Grande do Sul (IPERGS), que foi destinada ao assentamento 19 de Setembro.

Durante o processo de assentamento, as famílias passaram a valorizar os seus direitos coletivos, ou se- ja, tudo o que dizia respeito aos interesses da comunidade política. Após a conquista da terra, o acesso aos serviços locais de saúde também passou a fazer parte da sua pauta de reivindicações diante do governo municipal. A negociação do acesso foi lenta e repleta de conflitos com setores contrários a reforma agrária, mas os assentados também encontraram aliados políticos na cidade, o que ajudou a levar adiante suas mobilizações.

A primeira conquista foi à visita do secretário de saúde do município, ainda nos primeiras semanas após o estabelecimento das famílias na área destinada pelo governo estadual. Alguns meses depois, eles conseguiram que a prefeitura distribuísse água com o carro-pipa duas vezes durante a semana e uma reserva de fichas para atendimento médico no posto de saúde de um bairro popular localizado nas imediações do assentamento. Ainda nos primeiros anos, após muita pressão por parte dos assentados, a prefeitura fez uma estrada de chão ligando a BR-116 e a agrovila, uma escola de ensino básico dentro do assentamento, além de ter contribuído na efetivação de algumas obras iniciais de saneamento básico, pois as terras sofriam inundações constantes durante o inverno, o que causava sérios problemas respiratórios, como bronquites, gripes e outras complicações.

A demanda não foi dirigida apenas para o poder público local, pois o sistema de distribuição de água nas residências foi construído com o financiamento de uma Organização Não-Governamental (ONG) internacional, tendo como instituição mediadora a igreja católica do município. As primeiras ações no que se refere à segurança alimentar foram fundamentais para a permanência dos assentados na área. Como o governo não ofereceu nenhum auxílio técnico inicial e esperou quase seis meses pra liberar os primeiros recursos, foi necessário garantir a alimentação de cerca de 6 o pessoas, o que não é nada fácil. Os assentados foram buscar ajuda no Movimento dos Trabalhadores Sem Terra (MST), nas organizações sindicais da localidade, igrejas e partidos políticos. Uma ampla rede foi mobilizada, o que permitiu superar o obstáculo mais difícil e com conseqüências mais graves no processo de implementação de assentamentos de reforma agrária: a segurança alimentar.

14 A terra ocupada foi uma fazenda localizada na região de Cruz Alta. 
No último ano, o assentamento teve uma demanda antiga atendida pela prefeitura municipal: a instalação de um Posto de Saúde na agrovila, com atendimento da equipe médica uma vez por semana. Com este novo recurso, já não é mais necessário deslocarse até a vila Santa Rita, o entendimento ficou mais rápido e o acesso, facilitado. A inauguração do Posto foi comemorada com uma grande festa, que contou com a presença do representante do governo local, assentados da região, moradores da cidade de Guaíba e lideranças políticas locais. A mobilização por direitos coletivos continua, pois as famílias já estão trabalhando numa nova bandeira de luta: um agente comunitário de saúde, que possa acompanhar a situação de cada uma das famílias, possibilitando a efetivação de um trabalho de prevenção.

\section{O Projeto de Extensão Universitária}

A idéia inicial do projeto de extensão surgiu a partir do programa "Convivência Rural”, oferecido aos estudantes pela Pró-reitoria de Extensão da Universidade Federal do Rio Grande do Sul (PROREXT). Em 1996, foi criado um convênio com a Cooperativa de Assentamentos Rurais do Rio Grande do Sul (COCEARGS), "visando estimular o intercâmbio entre a Universidade e assentamentos rurais do estado" ${ }^{15}$. Em agosto de 1999, esse programa incluiu, "entre as comunidades parceiras", o 19 de Setembro. Por um período de dez dias, durante as suas férias, estudantes de diferentes áreas do conhecimento visitaram o assentamento e realizaram um diagnóstico contemplando as áreas de saúde, educação e produção. Alguns meses depois, o Departamento de Educação e Desenvolvimento Social da PROREXT elaborou um projeto de extensão para ser desenvolvido no assentamento, tendo como referência esse diagnóstico. Esse projeto foi encaminhado ao "Programa Universidade Solidária", de onde vieram os recursos econômicos para a sua execução ${ }^{16}$.

O "UniSol" foi criado em 1995 pelo Conselho da
Comunidade Solidária. Segundo os seus idealizadores, esse programa teve como objetivo "mobilizar diferentes setores da sociedade e do Estado para trabalhar em municípios pobres de todo o país, visando colaborar para a melhoria da qualidade de vida de suas comunidades, contribuindo para o seu desenvolvimento sustentável". O trabalho de campo privilegiavam ações que envolviam as pessoas da comunidade, denominados "agentes multiplicadores", tendo em vista a conquista da "sustentabilidade dos trabalhos desenvolvidos". Os projetos aprovados em edital foram coordenados pelo setor de extensão das universidades e envolveram os seus estudantes, docentes e funcionários. $\mathrm{O}$ apoio financeiro veio de instituições locais, nacionais e internacionais ${ }^{17}$.

O projeto realizado no 19 de Setembro teve como objetivo "capacitar a comunidade do assentamento" para "redirecionar a matriz produtiva visando recuperar a [sua] sustentabilidade econômica" e "subsidiar a formulação de um Plano de Desenvolvimento Sustentável Integrado". Na sua primeira etapa (o1/200o), foram realizados cursos teórico-práticos envolvendo os seguintes temas: produção de arroz irrigado e piscicultura; formação de pomares domésticos; produção ecológica de hortaliças; e manejo integrado dos recursos naturais tendo em vista os seus impactos ambientais. Na segunda etapa (02/200o), foram realizadas novas atividades, como oficinas de educação ambiental, implementação de adubos verdes, produção agroecológica, saneamento, qualidade da água, doenças de veiculação hídrica e plantas medicinais. Também foram realizadas visitas orientadas em unidades produtivas e experimentais, localizadas em assentamentos rurais do estado e na Estação Experimental da UFRGS. Participaram dessas atividades os "agentes multiplicadores" já mencionados, escolhidos entre os membros da "comunidade", e os integrantes da equipe de extensão ${ }^{16}$.

O projeto contou com uma equipe executora formada por seis funcionários, 10 professores ${ }^{18}$ e 27 es-

\footnotetext{
15 UNISOL; SESU/MEC. Projeto: diretrizes para revitalização do espaço sócio-produtivo do assentamento 19 de Setembro em Guaíba, RS. Porto Alegre: Pró-Reitoria de Extensão da UFRGS, 200o. Habilitação ao Edital ol/200o

16 Título do Projeto: “Diretrizes para Revitalização do Espaço Sócio-Produtivo do Assentamento 19 de Setembro, Guaíba - RS”. Edital o1/200o - SESU/MEC - Unisol.

17 UNISOL. Universidade Solidária. Disponível em <http://www.unisol.org.br/site/pagina.php?idconteudo=2> Acesso em: 14 out. 2006. 18 Esses professores prestaram consultoria em áreas específicas, como desenvolvimento rural, sustentabilidade, arquitetura, planejamento urbano e ambiental. A maioria deles (8) são doutores ou doutorandos.
} 
tudantes ${ }^{19}$, todos da UFRGS, provenientes das mais diferentes áreas do conhecimento: arquitetura, agronomia, ciências sociais aplicadas, engenharia, enfermagem, medicina e direito. As intervenções da equipe de extensão tiveram como referência uma visão multidisciplinar e participativa do processo de construção do conhecimento, envolvendo a comunidade na definição dos problemas e na elaboração de estratégias de superação. Após um levantamento dos principais obstáculos para a autosustentabilidade do assentamento, buscou-se discutir alternativas para superálos Essas ações abrangeram áreas diferenciadas, a maioria delas relacionada, mesmo que indiretamente, à promoção da saúde coletiva do "19 de Setembro".

No que se refere a qualidade do solo, fator que está interligado com a segurança alimentar dos assentados e sua saúde individual, é possível pontuar algumas ações. Para proteger o solo mais seco da erosão e fortalecer a sua qualidade estrutural ${ }^{20}$, experiências com adubação verde foram implementadas em Unidades de Teste e Validação (UTV's), onde os agricultores e extensionistas tiveram a oportunidade de verificar a adequação dessas tecnologais ao meio ambiente local. Ao mesmo tempo, para resolver os problemas de alagamento da parte mais baixa do assentamento, o projeto introduziu um estudo de sistemas de drenagem de baixo custo (as tecnologias disponíveis no mercado são muito caras). Em vez dos canos corrugados envolvidos em material do tipo bedim, foram construídos drenos com materiais alternativos, como taquara e casca de arroz.

No que se refere à matriz produtiva do assentamento, em um primeiro momento, procurou-se evidenciar os interesses dos assentados, para depois buscar alternativas de superação das limitações ambientais (tendo em vista o aumento da qualidade do alimento e da geração de renda). Quando o projeto teve início, o sistema de produção do assentamento estava voltado para produção de leite, hortaliças e subsistência, mas atualmente alguns assentados estão produzindo arroz para comercialização. Os principais fatores de restrição da pecuária leiteira são: falta de forragem para os animais, devido às limitações dos recursos naturais (já comentados), e problemas jurídicos relacionados com a venda do leite in natura. No que se refere a produção de hortaliças, o projeto investiu em cursos de agroecologia, buscando agregar valor final ao produto.

Considerando que a saúde e a qualidade de vida dos assentados depende da qualidade ambiental, e tendo em vista que boa parte das doenças mais comuns no assentamento são causadas pela baixa qualidade da água, a equipe de extensão buscou aprofundar ainda mais o diagnóstico das condições de saneamento básico da agrovila, ao mesmo tempo em que procurou alternativas de tratamento dos afluentes domésticos do assentamento. Algumas experiências iniciais foram feitas neste sentido, com bons resultados até o presente momento. Essas alternativas exigem um investimento inicial de baixo custo na sua implementação, utilizando-se de materiais de fácil acesso.

O projeto de extensão conseguiu alcançar bons resultados, apesar de esbarrar em problemas relacionados a um certo desconhecimento, por parte dos técnicos, sobre a história social das famílias assentadas no 19 de Setembro, antes e após a conquista da terra. O principal obstáculo foi ampliar a utilização das tecnologias introduzidas através do projeto para o conjunto de assentados, pois a maioria dos avanços ficaram reduzidos às experiências implementadas nos lotes dos assentados interessados. Como veremos à seguir, a partir da descrição do projeto da farmacopéia, esse problema está relacionado a dificuldades enfrentadas pelas famílias ainda nos primeiros anos de implementação do assentamento.

\section{A Farmacopéia Popular}

Através da convivência prolongada com a comunidade, os extensionistas perceberam que boa parte das famílias utilizava plantas medicinais para tratar pequenos problemas de saúde, foi assim que surgiu a idéia de implementar um horto medicinal no assentamento. Esse trabalho teve os seguintes objetivos: reunir o conhecimento dos assentados sobre fitoterapia

\footnotetext{
19 A equipe discente inicial era composta de dez estudantes de arquitetura; cinco de agronomia; quatro de ciências sociais aplicadas; dois de biologia; dois de engenharia; e quatro de medicina e enfermagem. A maioria deles estava cursando os últimos semestres de graduação.

200 solo mais seco é muito importante para produção de alimentos para os assentados e animais (representa apenas 10\% da área).
} 
e relacionar as plantas utilizadas em um único álbum herbário; organizar grupos de trabalho interessados em manter uma farmácia comunitária; aproximar o horto medicinal e a escola; integrar a farmácia comunitária e o horto medicinal com outros assentamentos da região. Estudantes das áreas de biologia, enferma- gem, farmácia e medicina ficaram responsáveis pelo desenvolvimento do projeto junto à comunidade.

Ainda na fase inicial do trabalho, foi feito um levantamento do conhecimento etnobotânico das famílias, com a listagem do tipo de planta, uso medicinal, forma de utilização e cultivo.

\section{Tabela I - Plantas utilizadas no assentamento 19 de Setembro}

\begin{tabular}{|c|c|c|c|}
\hline Planta & Uso Medicinal & Forma de Utilização & Cultivo \\
\hline Abacate & Rins, regular pressão & Chá das folhas & $\operatorname{sim}$ \\
\hline Alcachofra & Pressão alta, dor de estômago, colesterol, diabetes & Chá com as folhas & $\operatorname{sim}$ \\
\hline Alecrim & Calmante & Tempero, chá & $\operatorname{sim}$ \\
\hline Arruda & Para dor de cabeça e para simpatia & & $\operatorname{sim}$ \\
\hline Babosa & Cicatrizante & Xarope & $\operatorname{sim}$ \\
\hline Bálsamo & Calo inflamado, cicatrizante & Pomada, lavagem com chá & $\operatorname{sim}$ \\
\hline Boldo & Fígado, estômago & Chá & $\operatorname{sim}$ \\
\hline Capim cidró & Calmante, baixa pressão & Chá & $\operatorname{sim}$ \\
\hline Calêndula & Anti-alérgica, anti-séptica & & \\
\hline Camomila & Calmante, cólica, estômago, garganta & Flor com leite (para garganta), chá & Sim e espontânea \\
\hline Carqueja & Dor-de-barriga, diarréia & & Espontânea \\
\hline Cabelinho-de-porco & Rins & & Espontânea \\
\hline Catinga-de-mulata & Cólica, para estômago e fígado & $\begin{array}{l}\text { Frita no óleo e passa no umbigo } \\
\text { da criança, chá }\end{array}$ & $\operatorname{sim}$ \\
\hline Chuchu & Baixa a pressão & Chá das folhas & \\
\hline${ }^{*}$ Couve & Hemorragia & Suco & \\
\hline Confrei & Cicatrizante, tóxica & Pomada & $\operatorname{sim}$ \\
\hline Canela & Cólica, estômago (gastrite), abortivo (altas doses) & & \\
\hline Endro & intestino, estômago & chá com folhas e sementes & Sim \\
\hline Eucalipto & Expectorante & Inalação, chá, sabão (perfume) & \\
\hline Erva cidreira & Calmante, baixa a pressão & Decocto ou chá com as folhas & $\operatorname{sim}$ \\
\hline Erva de Sta. Maria & Vermífugo, tóxica, para zumbido no ouvido & Tintura & Espont / cultiv \\
\hline Funcho & Cólica, gases & & Sim \\
\hline Gunchuma / Guanxuma & Picada de inseto, rins & Lavagem com as folhas, raiz & Espontânea \\
\hline Guaco & Expectorante & Chá & Sim \\
\hline Gervão & & & Espontânea \\
\hline Hortelã & Calmante, vermes & & $\operatorname{sim}$ \\
\hline Laranjeira & Calmante, gripe & Chá (flor e folha) & $\operatorname{sim}$ \\
\hline Losna & Estômago, fígado & Chá & Sim \\
\hline Manjerona & $\begin{array}{l}\text { Cólica, gases, dor-de-barriga. Em altas doses } \\
\text { causa insônia em crianças }\end{array}$ & & $\operatorname{sim}$ \\
\hline Maracujá & Calmante, baixa a pressão & & $\operatorname{sim}$ \\
\hline Malva & Infecção & Pomada & $\operatorname{sim}$ \\
\hline Malva-cheirosa & Infecção, afecções dos ovários & Chá e banho de assento & $\operatorname{sim}$ \\
\hline Margarida & Calmante & Folha em chá & Sim \\
\hline
\end{tabular}




\section{Tabela I (continuação)}

\begin{tabular}{|c|c|c|c|}
\hline Planta & Uso Medicinal & Forma de Utilização & Cultivo \\
\hline Mil-em-rama & Cicatrizante e para cólicas & Chá e pomada & $\operatorname{sim}$ \\
\hline Marcela & Estômago & Chá & Espontânea \\
\hline Noz moscada & Vômito (antiemético) & & \\
\hline Pata-de-vaca & Diurético & & \\
\hline Pitangueira & Diarréia, regulador de pressão & Folhas em chá & \\
\hline Picão & Rins, reumatismo e para digestão & chá da raiz & Espontânea \\
\hline Penicilina & Garganta, alergias & Gargarejo e banho & $\operatorname{sim}$ \\
\hline Poejo & Gripe, tosse & & $\operatorname{sim}$ \\
\hline $\begin{array}{l}\text { Ponta-alívio/Erva-da- } \\
\text { pontada (tb. novalgina) }\end{array}$ & Dor de cabeça & Tintura & $\operatorname{sim}$ \\
\hline \multicolumn{4}{|l|}{ Salso chorão } \\
\hline Salsa & Estancar o sangue $\left(^{*}\right)$, Diurético & Folha, raiz & $\mathrm{C} /$ tempero \\
\hline $\begin{array}{l}\text { Sálvia-da-gripe, } \\
\text { sálvia-da-tosse }\end{array}$ & Gripe & chá das folhas & Sim \\
\hline Sálvia & Tristeza (cura o baço), excitante, emenagoga & & $\mathrm{C} /$ tempero \\
\hline Serraia, serralha & Digestivo & Tintura & Espontânea \\
\hline Tansagem & $\begin{array}{l}\text { Cicatrizante, infecção urinária, garganta, } \\
\text { ataca o fígado }\end{array}$ & Pomada, gargarejo, chá & Espontânea \\
\hline Tiririca & Anti-anêmico & & Espontânea \\
\hline Urtiga & Reumatismo & & Espontânea \\
\hline
\end{tabular}

Logo no início do projeto, uma especialista em fitoterapia, que estudou a utilização de plantas medicinais em comunidades amazônicas, ministrou um curso sobre técnicas de cultivo, colheita, secagem e armazenamento de plantas medicinais, assim como manipulação de tinturas, xaropes, pomadas, cremes e óleos. Durante o curso, os assentados entraram em contato com experiências bem-sucedidas na comercialização de medicamentos caseiros e passaram a ver na iniciativa a possibilidade de um retorno econômico a médio e a longo prazo. A partir do incentivo da equipe de extensão, formaram-se dois grupos diferenciados em torno do projeto: um composto de mulheres da "parte baixa" do assentamento, "setor A"; e o outro formado de mulheres que residem na agrovila, "setor B".

Apesar da insistência inicial dos estudantes em formar um único grupo, logo ficou evidente que isso não seria possível, pois a formação de dois grupos expressava redes diferenciadas de afinidades. Essas diferenças estavam relacionadas a tensões que acompanharam a ruptura da cooperativa ainda nos primeiros anos de formação do assentamento. As mulheres do "setor A" (parte baixa do assentamento) faziam parte das primeiras famílias que abandonaram a cooperativa para formarem um grupo de trabalho menor, cujos membros eram ligados por relações de parentesco e compadrio. Mais tarde, aos poucos, outros grupos também abandonaram a cooperativa. No entanto, o primeiro grupo ainda guarda a marca de ter sido o primeiro a romper com o projeto coletivo. Por outro lado, o grupo da parte baixa afirma que as mulheres da agrovila não conseguem se organizar, pois são "só discurso" e "pouca prática". Como elas falaram diversas vezes, "com a farmacinha lá de cima (agrovila) é a mesma coisa que na época da cooperativa, fica só na conversa”. Sem entrar no mérito da veracidade dessas afirmações, é importante afirmar que os dois grupos de mulheres também desenvolvem atividades juntas, principalmente, na relação com os agentes externos ao assentamento (festas, reivindicações coletivas e reuniões). 
Em outros projetos que foram desenvolvidos pela equipe de extensão, as atividades também só avançaram a partir de grupos de afinidades (parentesco e compadrio), constituídos durante o processo de formação histórica do assentamento e, em alguns casos, antes das famílias serem assentadas. A própria ruptura da cooperativa em grupos menores seguiu a lógica da afinidade, além de ser a expressão de uma série de tensões envolvendo uma desconfiança geral em relação à burocracia institucional necessária para manter uma cooperativa operando conforme as regras econômicas e jurídicas (técnico contábil, presidente, secretários, advogado etc.). Nosso objetivo aqui não é discutir a ruptura da cooperativa, mas indicar que os projetos de saúde desenvolvidos em assentamentos rurais devem sempre levar em conta o passado das famílias assentadas, assim como os dilemas vivenciados durante o próprio processo de assentamento.

Essa compreensão exige a consciência inicial de que o tempo da apropriação do projeto pela comunidade, mesmo numa situação em que o projeto é o resultado de um diálogo e de uma pesquisa-ação participativa, dificilmente acompanha o tempo das previsões orçamentárias das instituições financiadoras, que trabalham a partir de uma perspectiva de mudança quase imediata (a maioria dos projetos tem previsão de duração de um ano). Um dos maiores problemas das políticas públicas na área de saúde é que, na grande maioria dos casos, essas políticas não são concebidas considerando a necessidade de se estabelecer um diálogo com o sujeito social local, com a sua cultura e o seu modo de vida. A intervenção é geralmente pensada a partir da cultura dos interventores, suas próprias representações sobre o "outro", na maioria das vezes construídas a partir de estereótipos.

No caso do projeto de extensão desenvolvido no assentamento, a equipe buscou auxílio na antropologia para entender as dificuldades de comunicação com o grupo local. Mesmo no caso da farmacopéia, onde foi feito todo um trabalho de registro do saber local dos assentados sobre as plantas medicinais, o dilema da comunicação intercultural esteve presente no momento de pensar a forma de organização dos grupos de trabalho. Cabe ao antropólogo mediar esses desentendimentos e construir um espaço onde a comunicação seja possível. No caso aqui analisado, procuramos fornecer subsídios que pudessem auxiliar a equipe de extensão a entender melhor a forma como o projeto da farmacopéia foi apropriado pela comunidade: se por um lado os assentados não participavam das assembléias chamadas pelos estudantes para discutir a ampliação da prática de medicina alternativa para o “coletivo", em um movimento lento e contínuo essas práticas e saberes permearam as relações sociais, com a troca de conhecimentos, medicamentos e saberes dentro dos grupos de afinidades, permitindo um movimento reflexivo sobre o passado de cada sujeito envolvido no projeto. 0 olhar é sempre disciplinar, por isso, é necessário saber olhar para entender as estratégias de apropriação diferenciadas, as formas de conceber a organização que seguem lógicas diferentes, mas que são tão ou mais eficazes que as nossas próprias formas de saber fazer.

\section{Saberes Tradicionais, Gênero e Saúde Pública}

Talvez uma das especificidades da antropologia seja a forma de abordar as grandes questões humanas a partir de dados etnográficos sobre ambientes específicos, buscando descobrir as contribuições que o entendimento das comunidades locais pode dar para a compreensão dos grandes temas existenciais. 0 olhar etnográfico, quando voltado para as pequenas sutilezas do cotidiano, permite descrever como as "grandes questões" influenciam a vida de pessoas de carne e osso, seja nas aldeias, assentamentos ou em laboratórios, departamentos governamentais e instituições totais. A narrativa do antropólogo emerge de um mergulho descritivo na vida do dia-a-dia, onde ele encontra material para sustentar suas reflexões mais analíticas. Para além de divergências escolares (ou de escolas teóricas), existe algo que nós não estamos dispostos a abandonar: a tradição etnográfica. Seguimos, portanto, um saber fazer que é passado de geração para geração, algo que nos mantêm unidos como disciplina, apesar de todas as diferenças (Peirano, 1995).

Durante a efetivação do projeto de extensão, aos poucos a lógica institucional foi sendo apreendida nos usos cotidianos dos assentados e da equipe de extensão. 0 diferencial da extensão é que se trabalhou com a idéia de que o problema de saúde está relacionado a outros fatores, como segurança alimentar e produção agroecológica, qualidade do solo, cuidado com os ani- 
mais, tecnologias hidrossanitárias, meio ambiente e saúde coletiva. O problema da saúde foi abordado de forma interdisciplinar, procurando identificar as doenças mais recorrentes e sua relação com as limitações de caráter ambiental. A forma de intervenção também foi diferenciada, os objetivos e as ações da equipe de extensão foram discutidos antes com a comunidade, que teve participação na concepção das estratégias. 0 projeto foi concebido a partir de princípios de participação comunitária, adaptação técnica às limitações locais, pesquisa aplicada e formação intercultural (técnicos, estudantes e assentados).

A descrição do projeto de extensão, mais especificamente do projeto de farmácia caseira, permitiu que algumas diferenças em relação à intervenção do governo fossem apontadas. A experiência com a produção de medicamentos caseiros surgiu como uma tática para superar os problemas relacionados ao acesso aos remédios utilizados no tratamento de doenças mais comuns, mas que não necessitam de um atendimento clínico especializado. Esse projeto foi incorporado pelos assentados e implementado conforme a dinâmica local, chegando a reproduzir as tensões ocasionadas por conflitos que ocorreram durante o processo de assentamento.

A fabricação e o uso de medicamentos caseiros permitiram uma valorização do conhecimento tradicional da comunidade sobre doença e práticas terapêuticas, incentivando um movimento reflexivo, que permitiu a valorização dos saberes tradicionais passados de geração para geração. Ao mesmo tempo, o envolvimento das mulheres no projeto possibilitou um espaço de discussão das questões de gênero, ao mesmo tempo em que permitiu uma valorização do saber feminino sobre o cuidado familiar.

A principal diferença entre a ação do governo municipal e o projeto de extensão é que o primeiro consistiu em uma ação que facilitou o acesso a um sistema de atendimento que já existia, sem colocar em discussão a forma terapêutica, as concepções de doença, assim como as características sociais, culturais e ambientais da comunidade local. A lógica vigente teve como referência principal uma ação de inclusão implementada a partir do pressuposto de que o serviço público de saúde está voltado para o atendimento universal da doença individual, tendo por base o discurso da igualdade dos usuários em termos de direi- tos de acesso aos serviços. A intenção deste artigo é indicar que ações de inclusão na rede oficial de atendimento público na área de saúde - no caso dos assentamentos rurais - devem vir acompanhadas da implementação de ações complementares que tenham como objetivo o reconhecimento da especificidade dos problemas de saúde da comunidade, o que significa problematizar a discussão sobre doença, saúde, meio ambiente e cultura.

\section{Os Usos dos Dispositivos Institucionais e as Políticas de Acesso Diferenciado}

O sistema de atendimento clínico-hospitalar não é universal, mas se propõe a ser, o que é uma diferença importante. Nas sociedades complexas, as alternativas de assistência à saúde são inúmeras, constituindo aquilo que Helman denomina de "pluralismo médico". No caso da sociedade brasileira, o modelo da biomedicina pode ser denominado "oficial" na medida em que os seus pressupostos culturais e sociais estão legitimados pelo Estado. A maioria das políticas públicas e privadas voltadas para o setor de saúde dá prioridade ao tratamento médico hospitalar, legalmente sancionado como a alternativa "mais eficiente e objetiva” no que se refere ao tratamento de doenças. No entanto, além do sistema oficial existem outros, como é o caso, por exemplo, de uma série diversificada de práticas "informais" utilizadas por diferentes grupos sociais de nossa sociedade.

A segunda questão fundamental é que o modelo biomédico não pode ser abordado como um conjunto de práticas e saberes objetivos sobre a doença, como uma espécie de reconhecimento das leis da natureza, pois isso seria conceber o corpo humano, unicamente, como um corpo biológico, quando na verdade o corpo é também um instrumento de construção simbólica da sociedade, um signo a espera de significado. As concepções de risco, as práticas de precaução, as diferentes formas de conceber a doença e a saúde são instrumentos simbólicos de fabricação da sociedade e não podem ser abordados como algo isolado do contexto sociocultural mais abrangente.

Essas duas questões iniciais são fundamentais para pensar a tensão entre o universal e o específico e as políticas de saúde pública na área de assentamen- 
tos rurais ${ }^{21}$. A tensão entre a universalidade dos serviços e a alteridade dos usuários é o eixo principal de uma luta social em torno do controle dos dispositivos de poder que acompanham as intervenções nas condições de saúde das populações. Quando Foucault descreve o surgimento da medicina social entre os séculos XVII e XIX, ele vai buscar identificar a lógica acionada pela intersecção entre as noções de "governabilidade" e "população", e a sua relação na emergência de uma racionalidade própria do Estado moderno. Segundo o autor, essa nova "arte racional de governar" tem como principal objetivo o controle e a ordenação da população, pois dela depende a força do Estado. Para gerir essa população, é preciso, entre outras coisas, de uma política de saúde que possa intervir nas condições de vida, para modificá-las e impor normas (Foucaut, 1997, p. 81-86).

Foucault está interessado na articulação entre dispositivos, técnicas e mecanismos disciplinares que organizam o espaço social a partir do século XVIII, definindo o funcionamento das instituições (exército, escola, prisão e hospital). Este movimento é legitimado pelo discurso da universalidade dos procedimentos e sua aplicação uniforme. Essa análise considera o papel decisivo dos procedimentos e dispositivos tecnológicos na organização de uma sociedade, para depois evidenciar, a partir de uma operação historiográfica, os dispositivos disciplinares presentes numa tecnologia judiciária e científica que surge com o desenvolvimento do Estado-nação moderno.

No Brasil, a saúde pública sempre foi uma preocupação estratégica do Estado, sendo um dos eixos fundamentais de toda a ação governamental, pois a própria noção de "governabilidade" só é possível a partir de uma preocupação racional com a gestão das "populações”. Trata-se de uma economia governamental que produz um espaço disciplinar onde a razão de Estado predomina, seja através de decretos legislativos, seja através de operadores que atuam como interventores legítimos. Podemos mencionar, por exemplo, as ações que visam à institucionalização e fiscalização da profissão médica; as condições de saneamento urbano (incluindo as transformações da arquitetura urbana, que também estão relacionadas à economia urbana em geral - transportes, disposição dos bairros, praças e avenidas); a constituição de uma agência de pesquisa e estatística; as intervenções epidemiológicas e ações preventivas; o investimento no sistema clínico-hospitalar, com formação de parceria com o setor privado; a efetivação de políticas nacionais; e, finalmente, as ações mais recentes de ampliação do sistema e descentralização administrativa (municipalização da gestão e inclusão através dos conselhos comunitários), assim como as ações no campo de "atendimento diferenciado". Uma breve descrição geral desses serviços, suas continuidades e rupturas, as redes institucionais que perpassam o Estado e a sociedade, permitem efetivar de fato uma “arqueologia dos dispositivos de poder", voltando o olhar da antropologia para o centro produtivo da economia simbólica das sociedades complexas.

Por outro lado, também precisamos de um outro pressuposto importante: é impossível reduzir os funcionamentos de uma sociedade a um tipo dominante de procedimentos. Devemos questionar qual é o estatuto de muitas outras séries de micro-práticas cotidianas que não deram lugar a uma configuração discursiva nem a uma sistematização tecnológica. Esse questionamento inicial permitiu a Michel de Certeau levantar a hipótese "de que o sistema da disciplina e da vigilância, formado no século XIX a partir de procedimentos anteriores, esteja sendo, ele mesmo, vampirizado por outros procedimentos", menos visíveis e mais dispersos, e por isso mesmo muito mais eficazes e silenciosos. Uma análise que não privilegia o aparelho produtor, mas os procedimentos propriamente "populares", dispersos, heterogêneos, anti-sistemáticos, minúsculos e cotidianos, permitem abordar as maneiras de fazer, os usos subversivos dos processos que organizam a ordenação sociopolítica, formando a contrapartida dos consumidores. Devemos analisar o uso dos dispositivos por si mesmos, as margens de manobra permitidas aos usuários pelas conjunturas, operações que proliferam no seio das estruturas tecnocráticas e alteram o seu funcionamento por uma multiplicidade de táticas articuladas

21 Vale lembrar que a mesma problemática se aplica às políticas de saúde voltadas para o atendimento das sociedades indígenas, comunidades remanescentes de quilombos, classes populares, moradores de rua e outros tantos grupos sociais que colocam em questão a pretensão de universalidade do sistema de saúde coletiva a partir da sua alteridade. 
sobre os detalhes do cotidiano. Esses modos de proceder, essas artes de fazer, esses usos poéticos formam uma rede antidisciplinar, que é importante mencionar na análise das políticas públicas". 0 "usuário" do sistema é um microoperador de discursos e práticas, a sua arte consiste em jogar com os acontecimentos para transformá-los em ocasiões (De Certeau, 1994, P. 41-5).

O caso do projeto da farmacopéia popular ajuda a ilustrar as relações entre tecnologias de intervenção e as operações contrárias de subversão colocadas em práticas pelos sujeitos que são o alvo dessas políticas. A discussão sobre acesso diferenciado, alteridade cultural e desigualdade econômica consegue tencionar o paradigma do universalismo tecnocrático, pois permite o deslocamento do olhar do centro de produção econômica e simbólica (as instituições e seus operadores), para as margens (os usuários dos serviços). Os projetos de extensão universitária geralmente estão voltados para populações mais pobres, seja no campo ou na cidade. As concepções que orientaram a prática dos intervencionistas estão inseridas em uma política alternativa e complementar às ações institucionais implementadas pelo governo na área de saúde, como os serviços do Sistema Único de Saúde, ou até mesmo ações dos governos estaduais e municipais.

O uso que foi feito da estrutura disponibilizada pelo projeto de extensão foi muito mais amplo e diversificado do que os objetivos iniciais, pois o elemento dialógico e participativo aponta para uma "fusão de horizontes" entre o olhar do técnico e o sistema de conhecimento das populações, que são alvo de suas ações. Estamos falando aqui na capacidade de descentralizar o olhar da produção em direção aos usos cotidianos, aos saberes e às práticas tradicionais, buscando encontrar soluções locais para superar obstáculos de ordem econômica, cultural e social.

A escolha pela fitoterapia foi feita tendo em vista a sua situação econômica e a possibilidade de aproveitar um conhecimento disperso colocado em prática no espaço privado da família. A metodologia participativa e as noções de pesquisa-ação que acompanharam as atividades desenvolvidas pela equipe de extensão permitiram uma valorização do conhecimento tradicional, contribuindo para legitimar um saber que historicamente foi estigmatizado pelos agentes "oficiais” de saúde. A abordagem da doença em relação a um conjunto mais amplo de fatores ambientais, cultu- rais e sociais, permite abordar a saúde coletiva a partir de sua complexidade, reconhecendo o sujeito social como portador de valores culturais.

\section{Referências}

BERGER, Christa. Campos em confronto: a terra e o texto. 2. ed. Porto Alegre: UFRGS, 2003.

BRASIL. Costituição Federal: outubro de 1988. 8. ed. Porto Alegre: Verbo Jurídico, 2004.

CERTEAU, Michel de. A invenção do cotidiano. 6. ed. Petrópolis: Vozes, 1994. v. 1.

FERNANDES, Bernardo Mançano. Núcleo de Estudos, Pesquisas e Projetos de Reforma Agrária (NERA). DATALUTA - Banco de Dados da Luta pela Terra: relatório, 2004. São Paulo: FCT/UNESP, 2006. Disponível em: http://www2.prudente.unesp.br/dgeo/nera/telas/ projetos.htm. Acesso em: 10 jun. 2006.

FERNANDES, Bernardo Mançano. A formação do MST no Brasil. Petrópolis: Vozes, 2000.

FOUCAULT, Michel. Segurança, território e população. In: ___ Resumos dos cursos do Collège de France (1970-1982). Rio de Janeiro: J. Zahar, 1997. p. 79-86.

FOUCAULT, Michel. O nascimento da medicina social. In:_____ A microfísica do poder. 14. ed. Rio de Janeiro: Graal, 1999. p. 79-98.

GOHN, Maria da Glória. Teoria dos movimentos sociais: paradigmas clássicos e contemporâneos. 3. ed. São Paulo: Loyola, 2002.

NAVARRO, Zander et al. Pequena história dos assentamentos rurais no Rio Grande do Sul: formação e desenvolvimento. In: MEDEIROS, Leonilde (Org.). A formação dos assentamentos rurais no Brasil: processos e políticas públicas. Porto Alegre: UFRGS, 1999. p. 19-53.

NORONHA, José Carvalho de. Os rumos do Estado Brasileiro e o SUS: a seguridade social como política pública da sociedade e estado. Saúde e Sociedade, São Paulo, v. 14, n. 2, p. 31-38, maio/ago. 2005.

PAUL, Patrick. Transdisciplinaridade e antropoformação: sua importância nas pesquisas em saúde. Saúde e Sociedade, São Paulo, v. 14, n. 3, p. 72-92, set./dez. 2005.

PEIRANO, Mariza. A favor da etnografia. Rio de Janeiro: Relume Dumará, 1995. 
SCHMIDT, Benício V.; MARINHO, Nolasco; ROSA, Sueli. Os assentamentos de reforma agrária no Brasil. Brasília, DF: UnB, 1998.

SINDICATO DOS JORNALISTAS PROFISSIONAIS DO RIO GRANDE DO SUL. Nos bastidores da batalha. In: GÖRGEN, Frei Sérgio (Org.). Uma foice longe da terra: a repressão aos sem-terra nas ruas de Porto Alegre. 2. ed. Petrópolis: Vozes, 1991. p. 67-92. 